\title{
Vibration Analysis of Gasoline Engine Faults
}

\author{
${ }^{1,2}$ Suphattharachai Chomphan \\ ${ }^{1}$ Department of Electrical Engineering, Faculty of Engineering at Si Racha, \\ Kasetsart University, 199 M.6, Tungsukhla, Si Racha, Chonburi, 20230, Thailand \\ ${ }^{2}$ Center for Advanced Studies in Industrial Technology, Kasetsart University, \\ 50 Ngam Wong Wan Rd, Ladyaow, Chatuchak, Bangkok, 10900, Thailand
}

Received 2013-04-20, Revised 2013-08-13; Accepted 2013-08-28

\begin{abstract}
Vibration analysis of engine faults is an approach to diagnose the engine condition. This study presents a study of vibration analysis of the normal engine and the engine with three different fault conditions. The gasoline engine was selected in this study. The accelerometer has been used at the surface of the engine to measure the vibration in the form of acceleration for all possible directions. Three conditions of engine faults including the engine that is not smooth while idling, the engine that goes missing while idling and the engine that has no power are selected. Five vibration signal parameters including fundamental frequency, long term spectrum, energy, long term cepstrum and zero crossing rate, are computed from all databases. The significant differences between normal engine and the fault engines are concluded. It can be obviously seen that the signal parameters are able to discriminate all three conditions and the engine with normal condition.
\end{abstract}

Keywords: Vibration Analysis, Gasoline Engine, Fundamental Frequency, Long Term Spectrum, Energy, Long Term Cepstrum and Zero Crossing Rate, Accelerometer

\section{INTRODUCTION}

A vibration analysis of the engine with faults becomes interesting in recent years. Signal analysis is a challenging tool to apply with the fault diagnosis of the engine, since the advanced technology of signal processing has been developed. Therefore several appropriated techniques of signal processing are adapted to vibration analysis. The main purpose of this work is to develop a tool to assist the engine mechanic to diagnose the engine faults.

As for vibration analysis, the accelerometer has been widely applied at the surface of the engine to measure the vibration in the form of acceleration for all possible directions. Subsequently, the important features are extracted from the measured acceleration signals. These features represent the differences among all cases of the engine faults. At the beginning, the gasoline engines for personal cars have been chosen in this study since they have been widely used.

In 2005, the techniques of sound intensity have been used to analysis of engine front noise by (Hong and Bing, 2005). The source of noise was detected and the noise level was consequently reduced based on the signal processing techniques for the diesel engines.

As for engine-fault diagnosis, Sharkey et al. (2000) used cylinder pressure and vibration signal to diagnose the robust faults. Modgil et al. (2004) performed the diagnostics of vibration for the engine test cells. The vibration signal had preliminarily been employed especially for the marine engine by (Zhan et al., 2007). Moreover, Klinchaeam and Nivesrangsan (2010) used the vibration signal to monitor the valve clearance fault on a small four strokes petrol engine in 2010. It has been seen from many studies that the vibration signal plays a very significant role in the engine diagnosis. Therefore, this study applies the vibration signal in the gasoline engine diagnostics.

\section{MATERIALS AND METHODS}

\subsection{Experimental Design}

The experimental design is shown in Fig. 1. It can be seen that the vibration signals are collected into an engine vibration database and a fault engine vibration database as depicted in the top of Fig. 1.

Corresponding Author: Suphattharachai Chomphan, Department of Electrical Engineering, Faculty of Engineering at Si Racha, Kasetsart University, 199 M.6, Tungsukhla, Si Racha, Chonburi, 20230, Thailand 


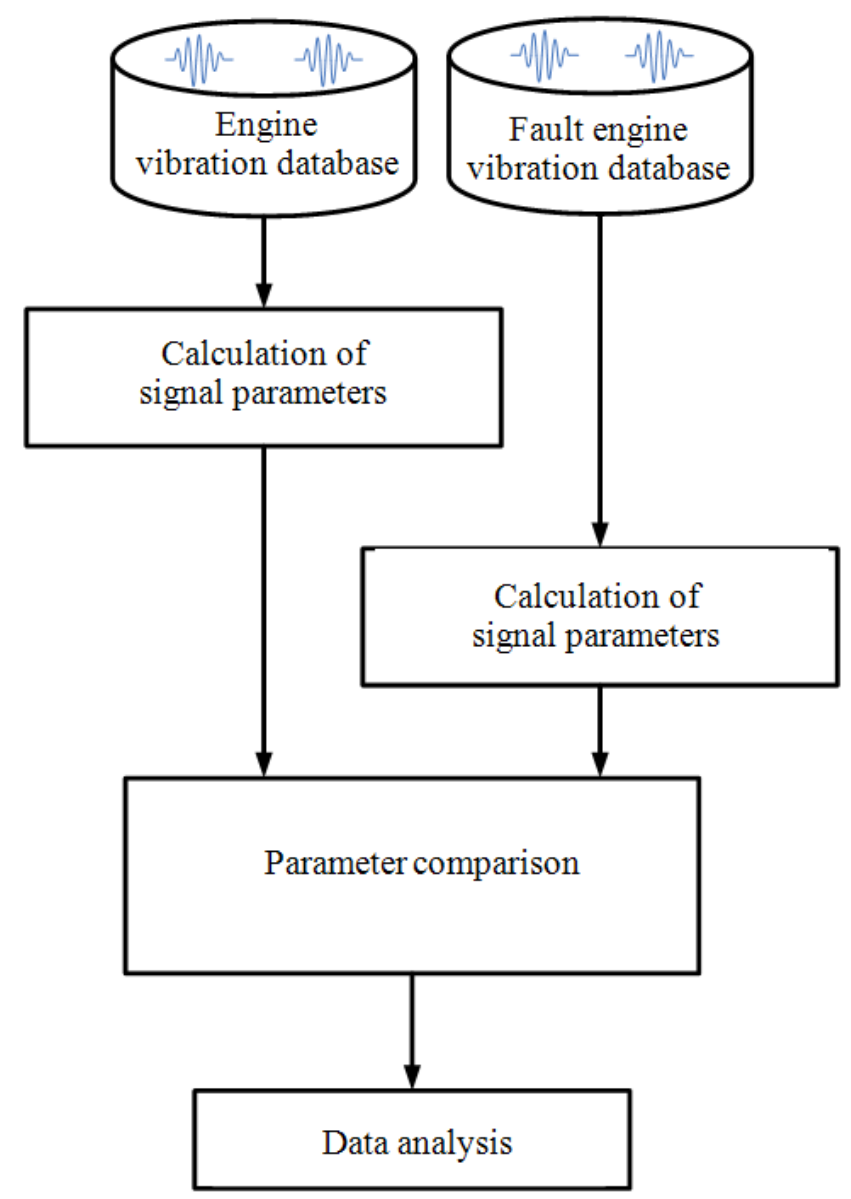

Fig. 1. Block diagram of the experimental design

After that, the calculation of signal parameters is performed both for the engine vibration database and the fault engine vibration database. The signal parameters from both databases are therefore compared. Then the significant differences between normal engine and the fault engines are empirically extracted from the presented figures. Finally the data analysis is conducted to summarize the differences between the normal engines the simulated fault engines.

From the preliminary study, three important conditions of engine faults are chosen from a number of conditions of engine faults which are normally found in the engine mechanic workshop. They can be listed as follows:

- $\quad$ Engine is not smooth while idling (ripple)

- Engine goes missing while idling (jerk)

- Engine has no power (powerless)
The gasoline engine with 4 cylinders of 1497-cc displacement is selected as a test bed, because its silent sound, well-known brand and economical spare parts.

\subsection{Parameter Extraction}

\subsubsection{Long Term Spectrum}

Fast Fourier Transform (FFT) analysis was employed. The sampling rate of the accelerator was set at 2,048 Hz. The analyzing window length was at 250 milliseconds and the overlap was $25 \%$. The symmetric Hamming window with 512 points was used (Leino, 2009).

Long term Cepstrum: Cepstral analysis is a nonlinear signal processing technique which is widely applied in speech signal processing and homomorphic filtering. It is noted that most of the detail occurs near the origin and in some peaks higher up the cepstrum. 


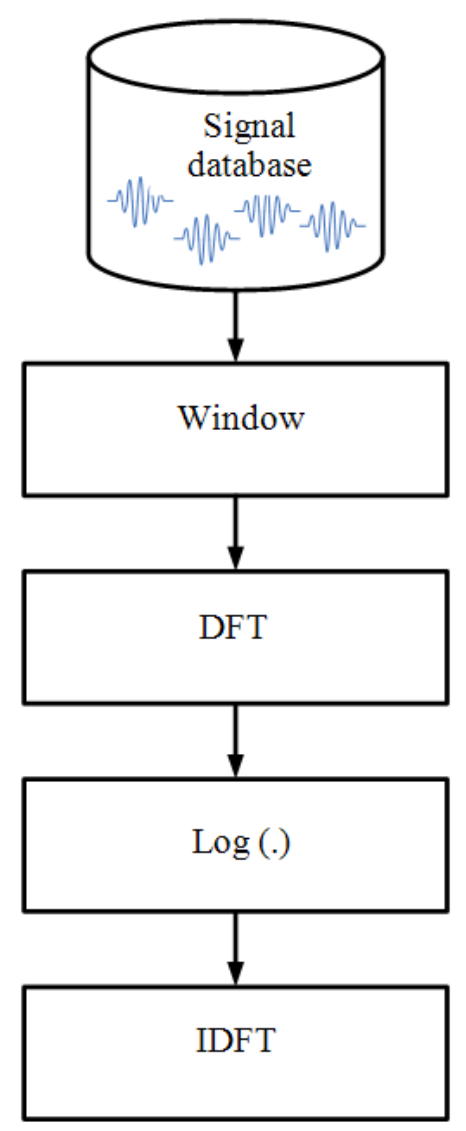

Fig. 2. Cepstral analysis procedure of the signal database

It has been seen that the lower ordered coefficients contain the envelope information. Meanwhile the remainder of the detail is mostly contained in the peaks which are separated by the pitch period and contain the fine detail information. The overall cepstral analysis procedure can be summarized in Fig. 2 (Leino, 2009).

Fundamental Frequency (F0): In the analysis of human speech signal, there is a significant amount of data on the frequency of the voice fundamental or fundamental frequency. This information has been published for many languages and for various types of discourse. The information always include an average measure of F0, basically expressed in $\mathrm{Hz}$, but in some cases the average duration of a period has been presented instead Waldstein and Boothroyd (1994). However, the F0 extraction is applied to the vibration signal. It is expected that some important frequencies may turn out.

Energy: A signal is often treated as a function of varying amplitude through time, it has been proved that the measurement of the strength of a signal would be the area under the curve in case of analog signal. However, this area may have a negative part. This negative part does not have less strength than a positive signal of the same size. It turns out that what we call the energy of a signal is the area under the squared signal. For a discrete signal, the energy definition is the sum of the squared magnitude of the samples (Waldstein and Boothroyd, 1994).

Zero Crossing Rate: As for a discrete signal, a zero crossing is defined when the successive samples of the signal or sequence have different algebraic signs. The rate at which zero crossings occur is a simple measure of the frequency content of a signal. Zero crossing rate is therefore a measure of number of times in a given time interval that the amplitude of the signals passes through a value of zero (Haraty and Ariss, 2007).

\subsection{Database Implementation}

The databases of the vibration signal are separated into two sets including an engine vibration database and a fault engine vibration database. As for the engine vibration database, thirty-second time interval vibration signals are recorded twice. As for each time, the signals contain three signals for three directions of $\mathrm{x}, \mathrm{y}$ and $\mathrm{z}$ axis. The sampling frequency of the accelerator sensor is $2,048 \mathrm{~Hz}$. Therefore each signal or sequence with 61,440 samples will be provided for each direction. Two channels are located at the pistons 1 and 4 . Moreover, the records of signals are divided into 2 periods of time including beginning period of engine start and the stable period after engine start.

As for the fault engine vibration database, there are three subsets for three important conditions of engine faults including the engine that is not smooth while idling (ripple), the engine that goes missing while idling (jerk) and the engine that has no power (powerless). Each subset performs the same way as that of the engine vibration database explained earlier.

\section{RESULTS}

The total signal is computed by taking sum square of all signals in three directions. They are shown in the following figures comparatively.

\section{DISCUSSION}

From Fig. 3 and 4, it can be seen that the zero crossing rate of the engine that is not smooth while idling (ripple) is much more frequently occurred than that of the engine with normal condition. 

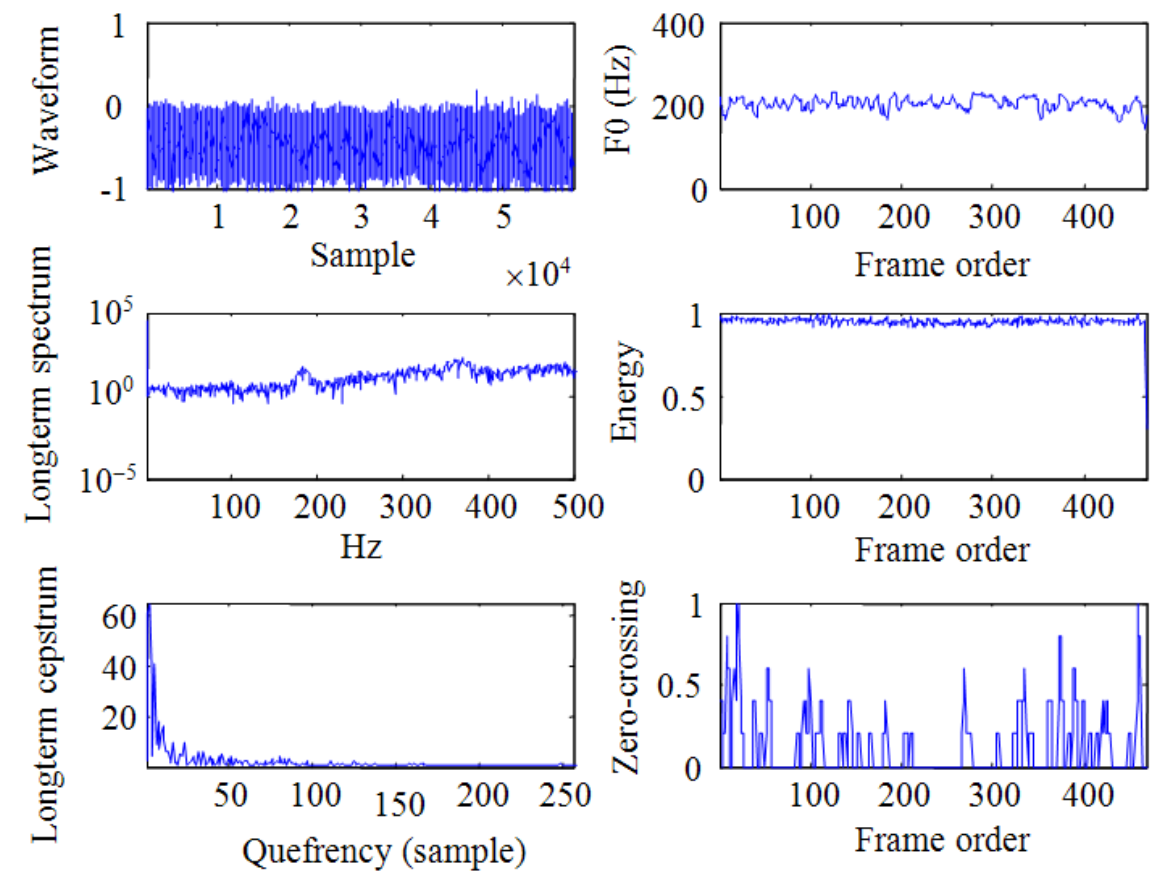

Fig. 3. Five parameters extracted from engine with normal condition
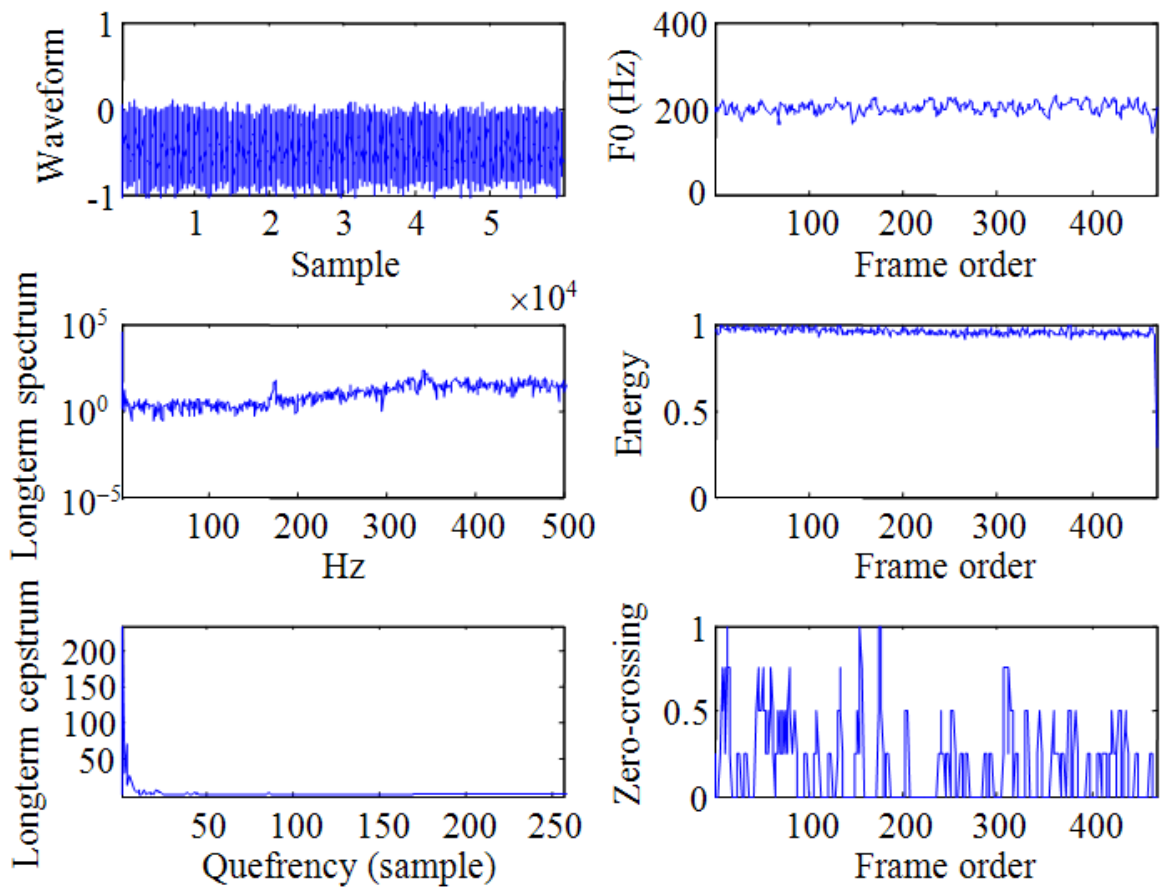

Fig. 4. Five parameters extracted from engine that is not smooth while idling (ripple) 

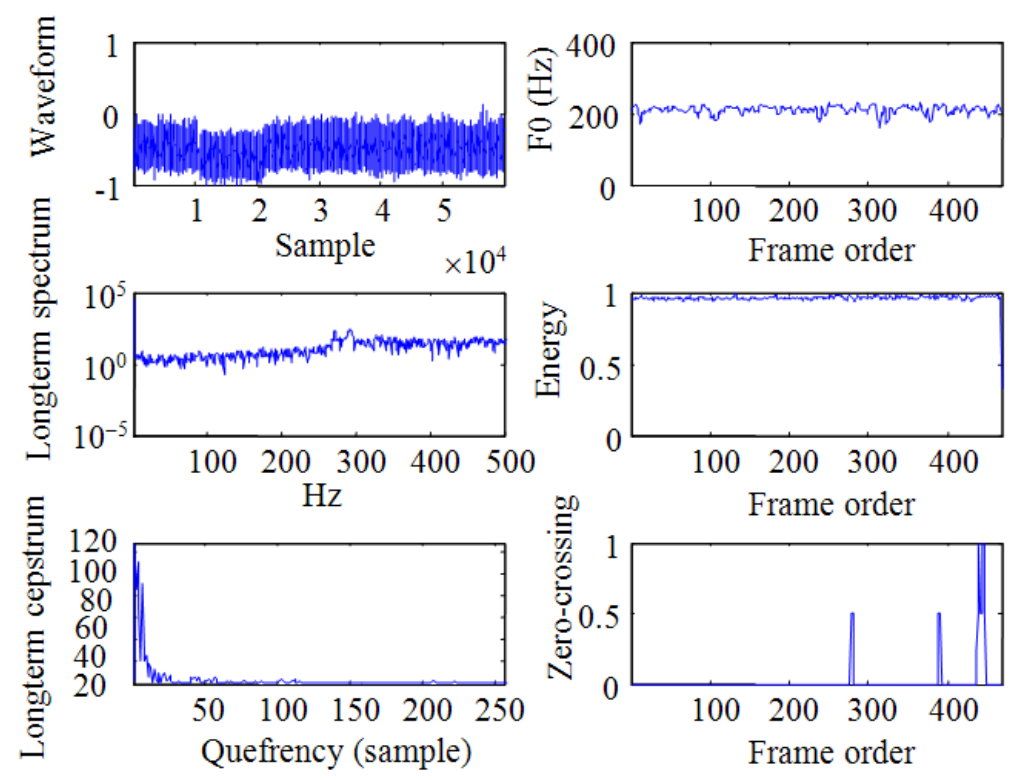

Fig. 5. Five parameters extracted from engine that goes missing while idling (jerk)

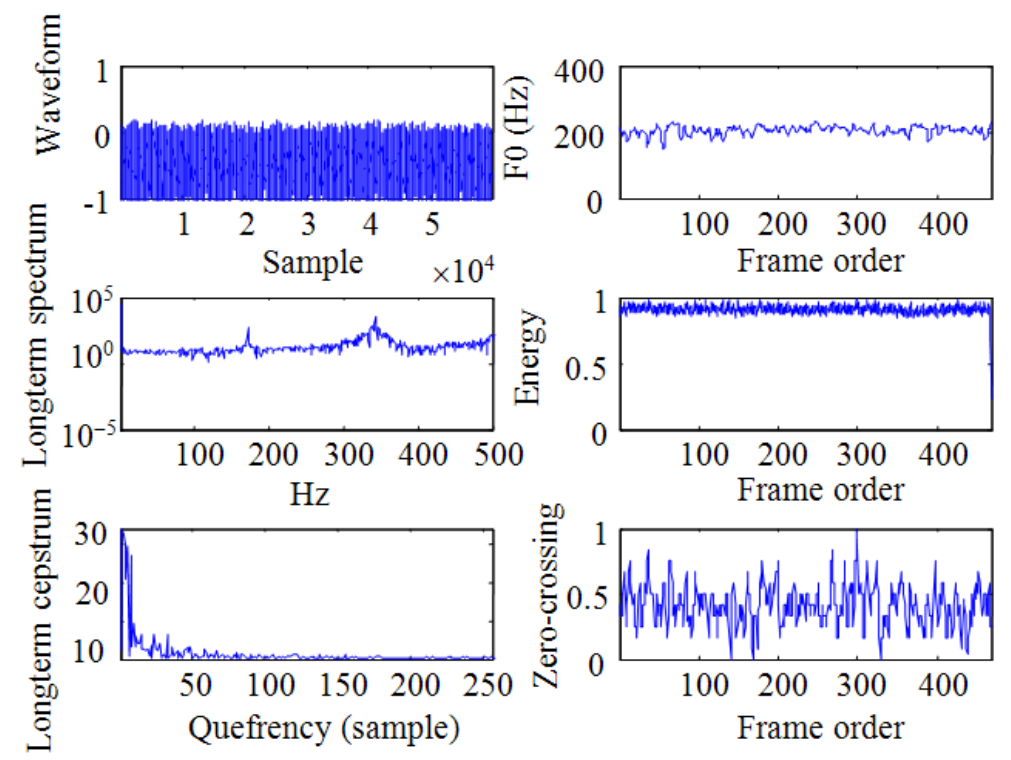

Fig. 6. Five parameters extracted from engine that has no power (powerless)

Moreover, as for the long term cepstrum, the component at low quefrency of the engine with ripple exists at the sample under 10, meanwhile the component at low quefrency of the engine with normal condition exists at the sample under 50 .

From Fig. 3 and 5, it can be seen that the zero crossing rate of the engine that goes missing while idling (jerk) is much less frequently occurred than that of the engine with normal condition. Moreover, as for the long term cepstrum, the component at low quefrency of the engine with jerk mostly exists at the sample under 20 as seen in Fig. 5.

From Fig. 3 and 6, it can be seen that the zero crossing rate of the engine that has no power (powerless) is much 
more frequently occurred than that of the engine with normal condition. From the long term spectrum, it has been noted that there are two periods of dominant components existing at around $150-200 \mathrm{~Hz}$ and $300-400$ $\mathrm{Hz}$ for the powerless engine, however it does not happen for the engine with normal condition. As for waveform, F0, energy and long term cepstrum, there is no significant difference between both cases.

\section{CONCLUSION}

This study proposes a study of vibration analysis of engine with three different fault conditions. Three conditions of engine faults including the engine that is not smooth while idling (ripple), the engine that goes missing while idling (jerk) and the engine that has no power (powerless) are provided. The engine vibration database and the fault engine vibration database were implemented. Five vibration signal parameters from both databases are calculated and then compared. The significant differences between normal engine and the fault engines are extracted from the presented figures. The signal parameters of F0, long term spectrum, energy, long term cepstrum and zero crossing rate are able to discriminate all three conditions and the engine with normal condition.

\section{ACKNOWLEDGEMENT}

The researcher is grateful to Kasetsart University, Si Racha campus for the research grants and Kasetsart University for the supports through the Center for Advanced Studies in Industrial Technology.

\section{REFERENCES}

Haraty, R.A. and O.E. Ariss, 2007, CASRA+: A colloquial arabic speech recognition application. Am. J. Applied Sci., 4: 23-32. DOI: 10.3844/ajassp.2007.23.32
Hong, Z.J. and H. Bing, 2005. Analysis of engine front noise using sound intensity techniques. J. Mechan. Syst. Signal Proc., 19: 213-221. DOI: 10.1016/j.ymssp.2004.03.007

Klinchaeam, S. and P. Nivesrangsan, 2010. Condition monitoring of valve clearance fault on a small four strokes petrol engine using vibration signals, Songklanakarin J. Sci. Technol., 32: 619-625.

Leino, T., 2009. Long-term average spectrum in screening of voice quality in speech: Untrained male university Students. J. Voice, 23: 671-676. DOI: 10.1016/j.jvoice.2008.03.008

Modgil, G., R.F. Orsagh and M.J. Roemer, 2004. Advanced vibration diagnostics for engine test cells. Proceedings of the IEEE Aerospace Conference, Mar. 6-13, IEEE Xplore Press. DOI: 10.1109/AERO.2004.1368143

Sharkey, A.J.C., G.O. Chandroth and N.E. Sharkey, 2000. Acoustic emission, cylinder pressure and vibration: A multisensor approach to robust fault diagnosis. Proceedings of the IEEE-INNS-ENNS International Joint Conference on Neural Networks, Jul. 24-27, IEEE Xplore Press, Como, pp: 223-228. DOI: $10.1109 / \mathrm{IJCNN} .2000 .859400$

Waldstein, R.S. and A. Boothroyd, 1994. Speech reading enhancement using a sinusoidal substitute for voice fundamental frequency. Speech Commun., 14: 303312. DOI: 10.1016/0167-6393(94)90024-8

Zhan, Y.L., Z.B. Shi, T. Shwe and X.Z. Wang, 2007. Fault diagnosis of marine main engine cylinder cover based on vibration signal. Proceedings of the 6th International Conference on Machine Learning and Cybernetics, Aug. 19-22, IEEE Xplore Press, Hong Kong, pp: 1126-1130. DOI: 10.1109/ICMLC.2007.4370313 